\title{
Lectores de Saavedra Fajardo en la Alemania ilustrada: Leipzig y la traducción alemana de Locuras de Europa
}

\author{
Sònia Boadas Cabarrocas \\ Universitat de Girona \\ sonia.boadas@gmail.com \\ Folke Gernert \\ Christian-Albrechts-Universität zu Kiel \\ folke.gernert@gmx.de
}

Fecha de recepción: 15/11/2010, Fecha de publicación: 18/11/2010

<URL: http://www.studiaaurea.com/articulo.php?id=142>

\section{Resumen}

Se analiza la recepción de Diego de Saavedra Fajardo en la Alemania ilustrada del sigloxviII, donde se imprimieron y tradujeron algunas obras de este autor. A través del análisis del prólogo que precede la edición alemana de Locuras de Europa, conoceremos el universo editorial que impulsó su aparición en Leipzig y la conyuntura histórico-política que lo propició.

Palabras clave

Diego de Saavedra Fajardo, Locuras de Europa, Die Thorheiten von Europa, Die Gelehrte Republic.

\footnotetext{
Abstract

Saavedra Fajardo's readers in illustrated Germany: Leipzig and the german translation of Locuras de Europa

This paper studies the reception of the Spanish writer Diego de Saavedra Fajardo in 18th century Germany. Several of his works were translated and printed there at the time. Through the analysis of the prologue preceeding the German translation of Locuras de Europa we learn many details about the editorial universe of the Enlightenment in Leipsic. Also of interest in this translation are the historical and political constellation that originated the publication of this work of Saavedra Fajardo.

Key words

Diego de Saavedra Fajardo, Locuras de Europa, Die Thorheiten von Europa, Die Gelehrte Republic.
} 
A finales del siglo xviı y a lo largo de todo el siglo xviII las obras del escritor y político murciano Diego de Saavedra Fajardo despertaron un enorme interés entre los eruditos europeos. ${ }^{1}$ Muestra de la formidable difusión que tuvieron sus textos son las numerosas reimpresiones en Espańa y las distintas traducciones que aparecieron en varios países.

Si ojeamos el manual bibliográfico de Antonio Palau (1980: XVIII, 192199), veremos como en las páginas dedicadas al plenipotenciario español proliferan las reediciones de sus Obras Completas a lo largo de los años posteriores a su muerte. Lo mismo sucede con las obras exentas: contamos más de una treintena de ediciones españolas de Idea de un príncipe político cristiano, impresa por primera vez en 1640 en Munich; una docena de Corona Gótica (Münster, 1646) y más de veinticinco de República Literaria, aunque el texto apareció por primera vez en 1655 bajo el título Juicio de Artes y Ciencias y atribuido a Claudio Antonio de Cabrera. ${ }^{2}$

Sin duda alguna, la obra que gozó de más traducciones fue Idea de un príncipe, con tres traslaciones al italiano, una docena al latín, dos al francés, dos al alemán, una al inglés y una al holandés; ${ }^{3}$ seguida de la República Literaria con varias versiones en inglés, italiano, francés y alemán. El panfleto político que Saavedra gestó durante su estancia en el congreso de paz en Münster, Locuras de Europa, también tuvo sus traducciones. Se trasladó al alemán y recientemente se han descubierto varios manuscritos italianos que transmiten el texto. ${ }^{4}$

\section{Las traducciones alemanas de Saavedra}

Como acabamos de señalar, fueron tres las obras de Saavedra que tuvieron su correspondiente traducción alemana. ${ }^{5}$ La primera que vio la luz fue la temprana traslación de las Empresas políticas, sólo quince años después de su aparición

1. El presente trabajo forma parte del Proyecto de Investigación FFI2008-01417-FISO («Diego de Saavedra Fajardo y las corrientes intelectuales y literarias del Humanismo») financiado por el Ministerio de Ciencia e Innovación.

2. Sobre la autoría de República Literaria véanse Alberto Blecua (1984 y 2006) y García López (2002 y 2006).

3. A todas estas ediciones impresas tenemos que añadir otro testimonio manuscrito que hemos encontrado, una traducción italiana, seguramente basada en la primera edición de 1640. Lleva por título IDEA / D'UN PRINCIPE POLITICO CRISTIANO / Rappresentata in cento Emblema / DEDICATA AL PRINCIPE DELLE SPAGNE / DA / Don Diego Saavedra Faxardo, Cavaliero dell' / ordine di Santiago, del conseglio di S. M..$^{\text {tà }}$ / nel
Supremo dell'Indie, e suo Ambasciad. / Plenipotenziario ne' tredeci Cantoni, nella / Dieta Imperiale di Ratisbona, per il / Circolo e Casa di Borgogna, e nel / Congresso di Munster per la Pace / Generale. Se trata de una obra de 1091 páginas que se conserva en la Biblioteca Nacional de Francia, con signatura Ms. Italiens 1664.

4. Para la localización y descripción de estos manuscritos, véase Boadas Cabarrocas (en prensa).

5. Además de estas obras tenemos constancia de un pliego que apareció directamente en alemán firmado por Diego de Saavedra y Antonio Brun, titulado Antwort der Königlichen Hispanischen Herren Abgesandten/ auff diel von der Cron Franckreich/ bey angestellten Friedens Tractaten zu Münster inn Westphalen/ gethane Proposition: Sampt angeheffter anderer Proposition, Fürschlag/ und Erklä- 
en español, en 1655, cuando se publicó Ein Abris eines Christlich-Politischen Printzens in CI Sinn-Bildern und mercklichen Symbolischen Sprüchen en la imprenta de Johann Janssonio dem Jüngeren (Jan Janszoon) en Amsterdam. Según indica el mismo título, esta versión no partía del texto castellano sino que siguió una de las traducciones latinas que circulaban de la obra. ${ }^{6}$

Después del elogio a Saavedra que llevó a cabo Gregorio Mayans, así como la aparición de su edición de la República Literaria, ${ }^{7}$ esta obra se trasladó a varias lenguas europeas, ${ }^{8}$ y en 1748 también tuvo su correspondiente traducción al alemán con el título Die Gelehrte Republic (Leipzig, Gleditsch), traducida por el profesor Johann Erhard Kapp. ${ }^{9}$ Esta obra se publicó en la imprenta creada por

rung/ wiel und durch was Mittel/ zu einem beständigen allgemeinen Frieden/ zugelangen. Beschehen zu Münster dieses 1645. Jahrs. [S.1.]: [S. i.] 1645. Se conservan ejemplares en la Herzog-August Bibliothek en Wolfenbüttel (signatura: M: Gl 4146), en la biblioteca universitaria de Erfurt (01 - Jus.H. $8^{\circ} 00208$ (46)), en la Universitäts- und Landesbibliothek Sachsen-Anhalt de Halle (78 M 377, Kapsel (10)), en la Bayerische Staatsbibliothek de Munich (Res 4 Eur. 365,41) y en la Forschungsund Landesbibliothek de Gotha (01- Jus.H. $8^{\circ}$ 00208 (46)); otro ejemplar custodiado en la Herzogin Anna Amalia Bibliothek en Weimar fue destruido por un incendio que causó graves daños en los fondos de la biblioteca en 2004.

6. «Zu vor auß dem Spanischen ins Lateinisch; nun ins Deutsch versetzt». La primera traducción latina se publicó con el título Idea Principis Christiano-Politici: Centum Symbolis expressa. Bruxellae: Mommartius, 1649. El impresor Johann Karl Münch publicó por lo menos dos ediciones de la traducción latina, una en 1649 y otra en 1669.

7. Nos referimos a Oración en alabanza de las eloquentísimas obras de don Diego Saavedra Fajardo (1730) y a su edición revisada de República Literaria (Valencia, A. Balle a costa de Francisco Roveda, 1730). El interés del erudito valenciano por enaltecer la prosa de Saavedra y en especial su República, catapultó todavía más la difusión de sus textos por toda Europa.

8. Habían aparecido traslaciones al inglés, $R \boldsymbol{e}$ publick of Letters (Londres, Austen, 1727); al italiano, La Republica Letteraria (Pisa, Pompeo Polloni, 1747), y al francés République Littéraire (Lausanna, François Grasset, 1770), esta última promocionada por el mismo Mayans, como se puede inferir de su correspondencia con el impresor francés. En una carta de Gregorio Mayans a François Grasset del 11 de febrero de 1765 se puede leer: «Me alegro de que Vm. haya ofrecido publicar una traducción francesa de República literaria de Dn. Diego de Saavedra que confío será bien recibida». El francés no tardó en responder, y lo hizo el 9 de mayo de 1765: «Je vous addresserai dans quelques expéditions à Valence ou à Alicante l'original de la République Littéraire de Saavedra et quelques exemplaires de la traduction Françoise tant pour vous que pour vos amis». Pero antes de conseguir que este impresor diese a luz la versión francesa de su texto, Mayans ya había intentado convencer a Gabriel Cramer en una carta del 6 de marzo de 1751: «En caso de querer Vm. ejercitarse en traducir algún librito de la lengua espańola en la francesa, ninguna mejor que la República $\mathrm{Li}$ teraria de Don Diego de Saavedra Fajardo de la impresión que yo hice en Madrid, que es la más correcta, y es necesaria esta advertencia porque la que Vm. tiene de Alcalá, en la p. 8 del catálogo de los libros españoles, está llena de errores muy enormes. El lenguaje deste librito de Saavedra es castísimo y enmendado, y la obra es de ingeniosa y agradable invención, digno de estar en una y otra lengua» Mayans (1993: 424-425, 274).

9. El título completo reza: Die Gelehrte Republic durch Don Diego Saavedra, Ritter des St. JacobsOrden, Beysitzer des obersten Raths von Indien und Philipp des Vierten, Königs in Spanien, gevollmächtigten Gesandten, auf der Friedensversammlung zu Münster. Nebst Gregorii Mayans Lobrede auf die wohlgeschriebenen Werke des Saavedra, und des Herrn le $C^{* * * *}$ gelehrten Republic davon die beyden ersten Schriften aus dem Spanischen, die letzte aber aus dem Französischen übersetzet worden. Mit einer Vorrede und einigen Anmerkungen Herrn Joh. Erhard Kappens, Professoris zu Leipzig. La obra iba acompañada de un prólogo, de algunos comen- 

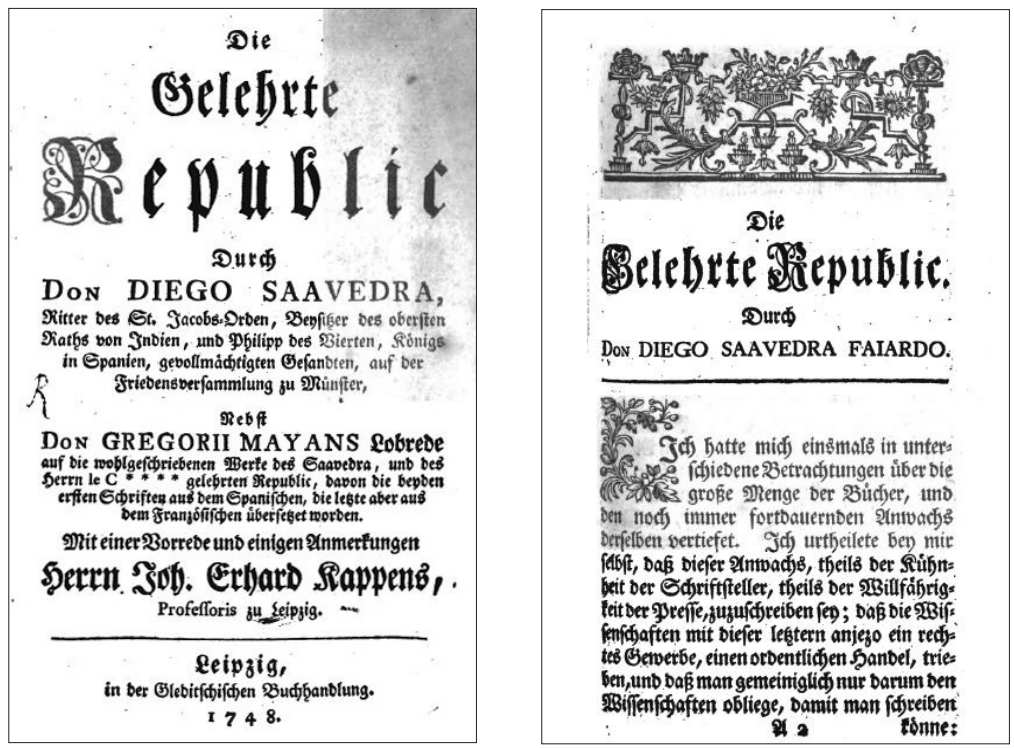

Figuras 1 y 2 .

Portada y pág. 3 de Diego de Saavedra Fajardo, Die Gelehrte Republic, Leipzig, Gleditsch, 1748.

Johann Friedrich Gleditsch, ${ }^{10}$ en la ciudad alemana de Leipzig, celebrada en Europa por ser un poderoso centro del comercio del libro y del negocio editorial.

La tercera y última obra que gozó de versión alemana fue el panfleto dialogado Locuras de Europa, que Saavedra acabó de redactar hacia 1646. Este texto castellano vio por primera vez la luz a mediados del siglo XviII, después de haberse difundido por todo el continente de manera manuscrita. ${ }^{11}$ Se trata de un

tarios del profesor Johann Erhard Kapp y de la traducción alemana de Oración en alabanza de las elocuentísimas obras de don Diego de Saavedra Fajardo, de don Gregorio Mayans. Johann Ehrhard Kapp (1696-1756) fue catedrático de retórica en la Universidad de Leipzig y alumno, a su vez, del bibliófilo Johann Burckhardt Mencke, uno de los lectores alemanes de Saavedra Fajardo. Sabemos que conservaba en su biblioteca ejemplares de República literaria (Alcalá de Henares, 1670), de Corona Gótica (Amberes, 1659) y de Idea de un principe político-cristiano (Amsterdam, 1659), véase Mencke (1727: 2, 389 y 523). Kapp poseía también una importante biblioteca que se vendió en subasta en 1758.

10. Para la historia de la Gleditsche Buchhand- lung, véase Gierl (1997: 358). La empresa se fundó en 1681 cuando Johann Friedrich Gleditsch, gerente de Johann Fritsch se casó con Katharina Margareta, la viuda de su jefe, descendiente de una familia de impresores, los Götze. En 1693 Gleditsch dejó la empresa a su hijastro Thomas Fritsch y fundó a su vez otra empresa que fue continuada por su primogénito, cuyo hijo comprará en el siglo XviII la librería de Fritsch. La hija de Gleditsch, Margareta, se casó con el erudito Johann Burckard Mencke, mencionado arriba. Véase para la familia del tipógrafo asimismo Brauer (1960: 917-926).

11. Sobre la enorme difusión manuscrita de Locuras de Europa véase Boadas Cabarrocas (en prensa). 

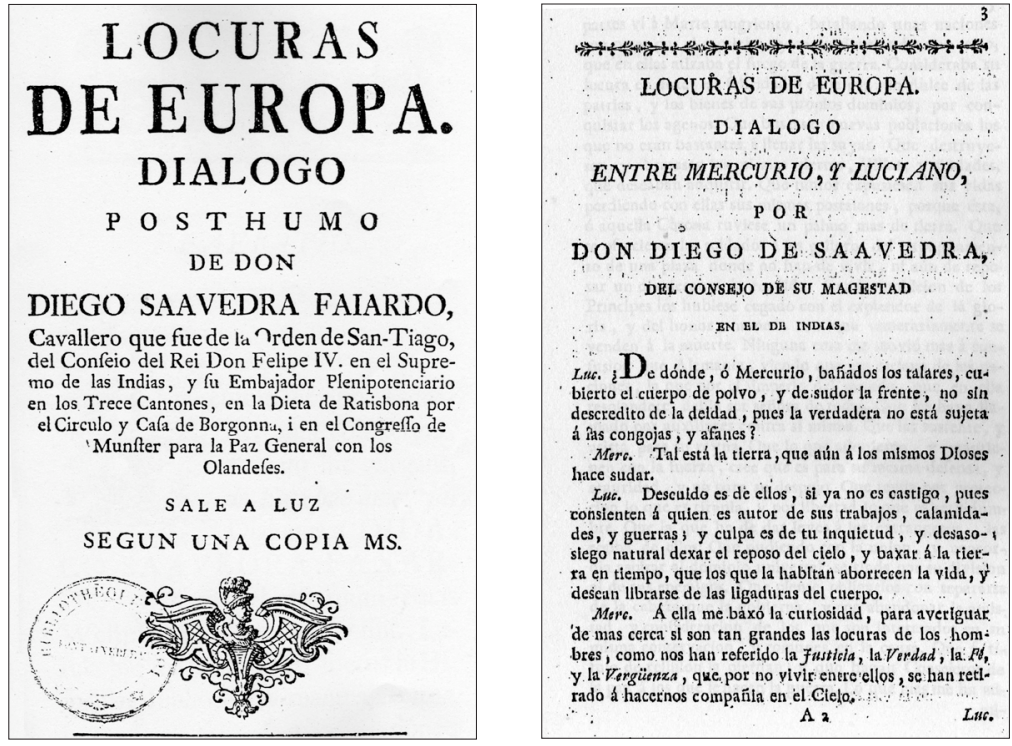

Figuras 3 y 4 .

Portada y pág. 1 de Diego de Saavedra Fajardo, Locuras de Europa, s.l., 1748.

ejemplar de 71 páginas con un prólogo introductorio en latín que comenta algunas de las noticias más importantes de la vida y obra del murciano. En la portada aparece una descripción detallada de los cargos que había ocupado Saavedra a lo largo de su carrera política, seguramente tomados de la portada de la segunda edición de las Empresas Políticas (Milán, 1642).

La obra se publicó por primera vez en 1748 sin indicación del lugar de edición, aunque muy probablemente se imprimiera fuera de Espańa como sospecharon ya en su momento algunos estudiosos. ${ }^{12}$ Nuestras recientes investigaciones sobre el texto de la obra, nos han revelado algunos problemas lingüísticos y varias dificultades con determinadas grafías que reforzarían esta hipótesis, ${ }^{13}$ apuntando, como ya infirieron a finales del siglo xIX algunos eruditos, a una imprenta alemana

12. «Pero por una feliz casualidad vino á nuestras manos un ejemplar impreso en 1748 en octavo, sin expresar el lugar de la impresión, que sin duda es extranjera, y al parecer de Amberes ó Bruselas», Saavedra Fajardo (1819: XVII).

13. En ningún caso aparece la grafía 'ñ', sino que para expresar el fonema los tipógrafos colocaban la 'n' por duplicado (Borgonna, sennalar, espannoles, duenno). Este hecho muestra que el taller donde se imprimió el testimonio no disponía de este tipo característico del alfabeto español. En el texto tampoco aparece el símbolo moderno de la vibrante múltiple (soccorerán, marazos, aborecidos, concurieron), y hemos detectado ciertos usos arcaicos de la cedilla (plaça, cabeças, coraçones, fuerças, flaqueças, fianças, esperança). Por otra parte percibimos un comportamiento un tanto extraño en la abertura fonética de las vocales, y más especialmente de la 'e' (paës, caëria, paeses bajos). 
como posible lugar de edición. ${ }^{14}$ Asimismo, el hecho de que don Antonio de Valladares y Sotomayor, el editor de la princeps española de Locuras de Europa (Saavedra, 1787), creyera publicar por primera vez una obra inédita avala esta conjetura.

Hasta la fecha pasó inadvertida la traducción alemana ${ }^{15}$ que fue publicada con el título Die Thorheiten von Europa en 1748 sin indicación alguna del lugar de edición. ${ }^{16}$ El texto iba acompañado de un interesantísimo prólogo al lector que estudiaremos a continuación haciendo particular hincapié en las informaciones que aporta acerca de las fuentes de la traducción así como de su fecha de redacción. En apéndice a este trabajo publicamos una traducción española del prólogo alemán.

Es curioso que un siglo después de su redacción, se publicara contemporáneamente la editio princeps española y la traducción alemana de Locuras de Europa y, además, fuera de España. Un análisis de la materialidad de los dos testimonios revela paralelismos llamativos entre ambos y contribuye así a explicar el repentino interés que cobró la obra del murciano en Alemania. En ambas ediciones se observa, además de una idéntica puesta en página del texto español y del texto alemán, una serie nada desdeñable de semejanzas: las mismas decoraciones de las iniciales, similares ornamentos florales en las cabeceras, la utilización de mayúsculas en pasajes análogos y la misma distribución de los diálogos (el nombre de los interlocutores aparece centrado y en cursiva mientras que las respectivas intervenciones empiezan en la línea siguiente). Además, la lista de cargos que se atribuyen a Saavedra es prácticamente idéntica en las dos publicaciones. A todo esto añada-

14. Vicente Salvá (1872: 299) conjetura la existencia de una posible edición alemana. Asimismo Brunet (1864: 17) y Grässe (1865: VI, 200) proponen al igual que Roche y Tejera (1884: XCIV) Alemania como lugar de impresión. Desconocemos hasta qué punto los citados estudiosos tuvieron a la vista el ejemplar en cuestión y lo examinaron, o simplemente se limitaron a recoger los juicios de los demás. En su edición, González Palencia (1964: 1195), igual que Dowling (1997: 123), se limita a resumir las opiniones anteriores. 15. Dowling (1997: 123) sospechaba que deberían existir traducciones de la obra: «We can only conjecture that he intended for it to circulate, and that it would have been more effective in a language other tan Spanish. Perhaps a scholar studying the history of the Thirty Years' War will some day discover a version of it in Latin, or French, or Dutch, or German.»

16. El título completo en alemán reza: Die Thorheiten von Europa in einem Gespräche, zwischen Mercurio und Luciano, vorgestellet von Don DIEGO SAAVEDRA, Philippi IV. Königs in Spanien, gevollmächtigten Gesandten auf dem
Friedens-Congreß zu Münster und Beysitzer des obersten Raths von Indien etc. darinnen der $\mathrm{Zu}$ stand von Europa, wie er sich in währenden Westphälischen Friedens-Handlungen befunden hat, freymüthig beurtheilet wird. Aus einer spanischen ungedruckten Handschrift ins Teutsche übersetzet. Im Jahr 1748. Ejemplares de esta traducción se conservan en muchas bibliotecas alemanas: Berlin (1 an:@Bibl. Diez oct. 8698), Göttingen (8 H UN IV, 5431 (1)), Jena (tres ejemplares con las signaturas 8 Art.lib.X,7(2); 8 Bud.Hist.lit.1(2) y 8 Bud.Ph.76), Rostock (JIb-3326.2), Wolfenbüttel (M: Ll 212, ejemplar digitalizado accesible en la página http://diglib.hab.de/drucke/ll212/start.htm, consultado el 1.9.2010) así como en la Landschaftsbiothek Aurich (signatura: O 161 (2)). Casi todas estas bibliotecas con la excepción delasúltimas conservan también un ejemplar de la edición española del mismo año: Berlin (8»@Xl 9261 y Bibl. Diez oct. 8698), Göttingen (8 H UN IV, 5430 y 8 H UN IV, 5431 (2)), Jena (8 Art.lib.X,7(3) y 8 Bud.Hist.lit.1(3)), Rostock (JIb-3326.1); otro ejemplar se halla en la Landesbibliothek en Schwerin (Ol V 1540). 


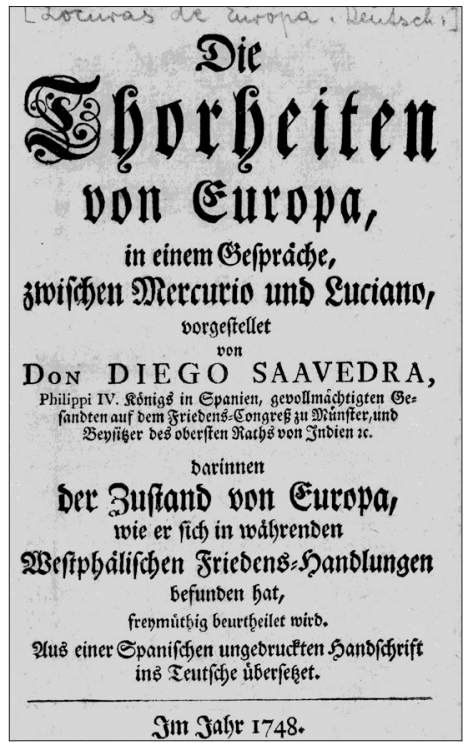

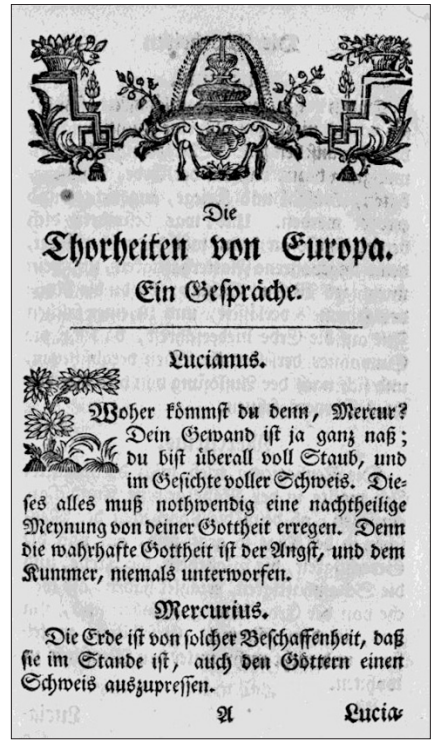

Figuras 5 y 6.

Portada y pág. 1 de Diego de Saavedra Fajardo, Die Thorheiten von Europa, s.l., 1748.

mos que el estudio ecdótico de ambos testimonios revela la presencia de errores comunes y lagunas de varia extensión en los mismos loci, singularidades que los remontan, sin duda, a un subarquetipo común. Podemos concluir entonces que ambas obras salieron de un mismo taller de imprenta que podemos identificar si relacionamos estos dos testimonios de Locuras de Europa con la traducción alemana de la República Literaria que fue publicada en $1748^{17}$ en la Gleditschische Verlagsbuchhandlung de Leipzig. Estos tres testimonios alemanes de obras del

17. Dos décadas después, en 1771 apareció en el taller de Felician Mangold en Praga otra edición alemana de República Literaria, bajo el título Die Republik der Gelehrten oder allegorische und kritische Beschreibung der Künste und Wissenschaften; welche von Dom Diego Saavedra Fajardo, Ritter des Ordens von St. Jago u.s.w. hinterlassen worden, und nach dessen Tode in Spanischer Sprache ans Licht getreten. Nach der Französischen Ausgaben (Staatsbibliothek Berlin: Bibl. Diez oct. 8697) donde se afirmaba que el texto se había tomado de la edición francesa publicada un año antes en Lausanne por François Grasset con el título La
Republique litteraire, ou description allegorique et critique des sciences et des arts. Ouvrage posthume de Dom Diego Saavedra Fajardo. Traduit de l'espagnol sur l'edition la plus correcte, publiée à Madrid en 1735. La traducción alemana se reimprimió en Jena-Leipzig por Gabler en 1807. Hemos localizado ejemplares en la Staatsbibliothek de Berlin (A 152) así como en Jena (8 Art.lib.X, 8) y en Weimar (16, 9: 5). La Niedersächsische Staatsund Universitätsbibliothek posee además un ejemplar (signatura DD93 A 33615) sin nombre de autor ni indicaciones tipográficas con el título Die Republik der Gelehrten, s.l.t.a. [ca. 1790]. 

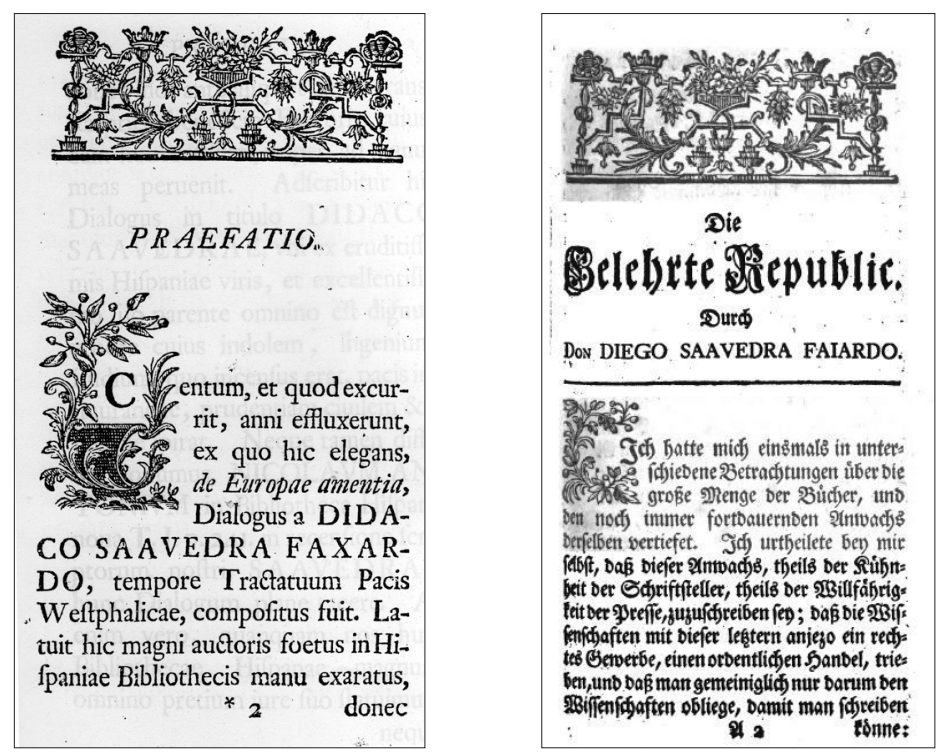

Figuras 7 y 8 .

Praefatio de Diego de Saavedra Fajardo, Locuras de Europa, s.l., 1748 y pág. 1 de Diego de Saavedra Fajardo, Die Gelehrte Republic, Leipzig, Gleditsch, 1748.

diplomático murciano presentan analogías en cuanto a la disposición del texto, el tamaño de las letras, la alternancia de los tipos góticos con los itálicos en los textos alemanes, las decoraciones florales colocadas al principio de determinadas páginas o los ornamentos de algunas iniciales. Queremos destacar también el hecho de que aparezca exactamente el mismo adorno en la primera página de Die Gelehrte Republic y en el prefacio en latín de la edición española de Locuras de Europa. Todas estas evidencias nos permiten concluir que las tres ediciones salieron del mismo taller de imprenta lipsiano. No es nada casual ni el lugar de publicación ni el momento en el que se lleva a cabo porque nos la habemos con una constelación histórica bastante parecida a la que originó Locuras de Europa unos cien años antes.

\section{La actualidad de Saavedra Fajardo en la Alemania ilustrada}

En 1740, después de la muerte de Carlos VI, emperador del Sacro Imperio Romano Germánico, se desató la Guerra de Sucesión Austríaca. María Teresa I, la hija heredera del emperador tenía que habérselas no sólo con las ambiciones al trono de Carlos Alberto de Baviera y de Augusto de Sajonia sino también con la codicia de algunas potencias europeas que intentaron aprovechar la ocasión para ampliar su territorio 
con la anexión de varias provincias. El principal enemigo de los Austrias fue el rey de Prusia, Federico II el Grande, quien ocupó en 1740 el territorio de Silesia ${ }^{18}$ aspirando a la anexión de la región polaca. Los bandos beligerantes en este conflicto se posicionaron rápidamente. Los aliados de Austria eran las Provincias Unidas, Gran Bretaña y Sajonia, que se enfrentaba con Prusia, acompañada de Francia y España que había empezado por su cuenta una guerra marítima con Gran Bretaña. Después de ocho años de guerra, la paz de Aquisgrán (1748) puso fin a los conflictos, manteniendo el statu quo ante bellum con la excepción de algunos territorios, como por ejemplo Silesia, que se concedió al rey prusiano. De esta manera Prusia se erigía como una de las principales potencias europeas y se convirtió en el principal enemigo de la Casa de Austria.

Leipzig, fue una de las ciudades alemanas que vivieron más de cerca este enfrentamiento bélico, no sólo porque Sajonia estuviera directamente implicada en el conflicto sino también por estar ubicada muy cerca de la frontera con Silesia.

Después de la muerte de Carlos IV y con los imparables progresos de Prusia, la Casa de los Habsburgo se veía en peligro y Europa revivía una situación política muy parecida a la del momento de la redacción de Locuras de Europa, cuando la monarquía francesa de los Borbones estaba poniendo fin al dominio europeo de los Austrias.

Si el panfleto que escribió Saavedra es un ataque a la política expansionista del enemigo y una apelación desesperada a la paz en un momento en que los Habsburgo se veían en clara inferioridad de condiciones, no es de extrañar que se reimprimiera y se difundiera la obra un siglo después, cuando se repetía la misma situación frente a una potencia distinta y se ponía de nuevo en evidencia la pérdida de poder de la Casa de Austria.

Teniendo en cuenta esta coyuntura política, se entiende mejor por qué en el siglo XVIII Locuras de Europa sigue siendo interesante para los lectores alemanes. De hecho, el traductor de Locuras de Europa identifica en su prólogo las aspiraciones a la hegemonía europea de los prusianos de su tiempo con las ambiciones de los franceses descritas por Saavedra Fajardo. El anónimo prologuista concluye con un alegato conmovedor que propone la Pax Westfálica como modelo histórico, válido para solucionar los problemas actuales: «Wir wünschen, daß dieser doppelte Ruhm unserm werthen Vaterlande auf die spätesten Zeiten erhalten, die von ihm daselbst angezeigte Gebrechen geheilet und sonderlich, daß in diesem, mit Gott angefangenen 1748 Jahre, in einer Teutschen Stadt, wie vor hundert Jahren zu Münster und Osnabrug geschehen ist, der so längst gewünschte Friede, nach so vielem Blutvergießen wieder hergestellet und das Gleichgewicht in Europa und Teutschland Freyheit erhalten werden möge». ${ }^{19}$

18. El antiguo territorio de Silesia ocupaba principalmente la actual zona de Polonia, pero también parte de la República Checa y de Alemania. 19. «Esperamos sobre todo que en el presente año del Señor de 1748 sea otra vez en una ciu- dad alemana — como lo fueron hace cien años Münster y Osnabrück- en la que se restablezca la deseada paz después de tanto derramamiento de sangre y que prevalezca el equilibrio en Europa y la libertad en Alemania» 


\section{El prólogo de Die Thorheiten von Europa y la transmisión de las obras de Saavedra Fajardo en Alemania}

El autor del prólogo alemán hace especial hincapié en la etapa de Saavedra como embajador plenipotenciario en Münster y en sus negociaciones con los diplomáticos franceses Abel Servien, conde de La Roche des Aubiers, y Claude de Mesmes, conde d'Avaux, enviados al Congreso por el Cardenal Mazarino. Para ello se sirve principalmente de publicaciones francesas escritas en la primera mitad del siglo XVIII. Las más citadas son las Négociations secrètes touchant la Paix de Münster et d'Osnabrück (1725), fuente de una gran cantidad de epístolas y material relativo al Congreso de paz, y el libro del jesuita Guillaume Hyacinte Bougeant titulado Histoire du traité de Westphalie, que apareció en 1744. En las páginas de este último son frecuentes los reproches a ciertas prácticas de Saavedra durante su estancia en Münster. Parece ser que el murciano difundió falsas noticias entre sus enemigos y que interceptó varias misivas para averiguar cuáles eran los propósitos secretos de los franceses. A partir de estas artimañas Bougeant valora las cualidades diplomáticas de Saavedra, afirmando que sólo había sido enviado a Münster para esperar la llegada de otro embajador más experimentado (Bougeant, 1744: III, 30).

Además, el prologuista intenta demostrar la autoría saavedriana de Locuras de Europa a través de una serie de interesantes paralelismos establecidos entre el panfleto y Corona Gótica, la ambiciosa obra historiográfica que escribió Saavedra en la ociosidad de las negociaciones para demostrar la ascendencia goda de los Habsburgo. En ambos textos el murciano recurre al Inventaire general de l'histoire de France (1579), obra del historiador francés Jean de Serres. En un pasaje determinado de la obra, Serres narra cómo el rey Clodoveo había matado al rey de los godos Amalarico y se había apoderado de la Galia gótica, anécdota que se retoma en Locuras (Saavedra, 2008: 414) y reaparece más detallada en Corona Gótica, como él mismo cita. Otro paralelismo evidente que vincula la redacción de Locuras y Corona es la alusión a una carta de Teodorico a Clodoveo para ejemplificar la imprudencia de despreciar la paz. Este ejemplo histórico se alude en Locuras (Saavedra, 2008: 411) y se vuelve a mencionar en Corona: «Un consejo de Teodorico, rey de los ostrogodos, dado en una carta escrita a su suegro Clodoveo sobre sus victorias en Alemania, cuyas palabras son: 'Oye en tales casos al que en muchos ha sido experto. Aquellas guerras me sucedieron felizmente, que las acabé con templanza porque vence muchas veces quien sabe usar de la moderación y lisonjea más la fortuna al que no se ensoberbece’» (Saavedra, 1946: 691).

Es evidente que la versión alemana de Locuras de Europa nos aporta también información esencial para comprender cuál era su difusión a mediados del siglo xviıI en Alemania y en qué ambiente intelectual se llevó a cabo su traducción. En el prólogo se precisa que el traductor obtuvo la copia manuscrita inédita del texto español mencionada en la portada („Aus einer spanischen ungedruckten Handschrift ins Teutsche übersetzet») de un generoso amigo: «Hemos conseguido una copia de este diálogo de un bienhechor nuestro, muy estimado, que ha pasado algu- 
nos años en España donde ha tenido ocasión de coleccionar algunos manuscritos». Proponemos identificar este mecenas con el barón Hans Dietrich von Schönberg, un bibliófilo alemán que solía viajar por España en búsqueda de libros. Puede que entre ellos se hallara nuestro manuscrito inédito de Locuras de Europa. Sabemos que Schönberg vino a Valencia en 1730 donde trabó amistad con Gregorio Mayans ${ }^{20}$ quien le iba a enviar más tarde un ejemplar de República literaria en el que se basó muy probablemente la traducción alemana de Kapp. ${ }^{21}$

A continuación, el prologuista atestigua haber visto publicado el texto en espańol, hecho que demuestra que a pesar de que ambas impresiones sean del mismo año, la edición española fue la primera que vio la luz. El estudio ecdótico de estas dos impresiones nos permite afirmar que se remontan a un subarquetipo común, y todo nos hace pensar que se trata del manuscrito, por ahora desaparecido, que se cita en el prólogo.

El análisis del prefacio que precede el texto de Die Gelehrte Republik nos proporciona unos indicios para poder establecer la cronología de impresión de los tres testimonios y fijar las fechas ad quem. Kapp escribe en el prólogo: «Die unlängst aus einem geschriebenen Exemplar zuerst ans Licht gestellten Locuras de Europa dieses Saavedra, welche man auch Teutsch unter dem Titul Die Thorheiten von Europa gedruckt, haben den Namen dieses großen Spaniers in Teutschland von neuem wieder ins Andenken gebracht und bekannter gemacht». ${ }^{22}$ Con la referencia al testimonio impreso alemán Die Thorheiten, Kapp nos descubre que antes de que apareciera Die Gelehrte ya circulaban las dos ediciones de Locuras. En resumen, en la imprenta de los Gleditsch se publicó en primer lugar el texto español, seguido de su traducción alemana y por último la versión germánica de República Literaria. Esta última fue reseñada en la revista Neuer Büchersaal der schönen Wissenschaften, aparecida en julio de 1748, que nos proporciona una fecha ad quem para los tres testimonios. ${ }^{23}$

Presentamos a continuación una traducción castellana del prólogo alemán que precedía la edición del Die Thorheiten de $1748 .{ }^{24}$

20. Véanse Mestre (2005:58) y Mayans (2002) así cómo Bas Carbonell (2004: 215-218) quien reúne informaciones interesantes acerca de las andanzas de Schönberg por España alrededor de 1730 21. El hecho de que la correspondencia entre Mayans y el barón de Schönberg se acabe en 1740, explicaría el desconocimiento que tuvo Mayans de la traducción y posterior impresión alemana de las obras de Saavedra. Dicho sea de paso que la biblioteca de Schönberg fue vendida en 1751 al jurista y síndico de la quiebra holandés Gerard Meermann (1722-1771). Sabemos que su biblioteca contaba con un ejemplar de Corona Gótica, impreso en la imprenta madrileña de Andrés García el 1670. Véase Meerman (1824: 114).
22. "La reciente edición impresa del texto manuscrito de Locuras de Europa de este Saavedra que se han publicado asimismo en alemán con el título Die Thorheiten von Europa han refrescado la fama de este gran español en Alemania» (Saavedra, 1748c: 107). Estamos preparando un estudio del voluminoso prólogo que precede la traducción alemana.

23. Véase «Die gelehrte Republic, durch Don Diego Saavedra» (1748).

24. A pie de página y entre corchetes hemos añadido información adicional, ya sean transcripciones de las obras a las que se hace referencia o bien indicaciones acerca de la identificación de escritores u otros personajes que aparecen citados. 


\section{Locuras de Europa}

Estimado lector.

Quizá algunos podrían considerar este diálogo la invención de una mente aguda, atribuido erróneamente al ingenioso Saavedra para poder juzgar con más libertad bajo el nombre de este español famoso el estado de la Europa de hace poco más de cien años. Sin embargo, tales personas se equivocan y nos complace aun más ver publicado el original espańol atribuido a Saavedra, uno de los mejores autores en dialecto [sic] castellano.

Hemos conseguido una copia de este diálogo de un bienhechor nuestro, muy estimado, que ha pasado algunos años en España, donde ha tenido ocasión de coleccionar algunos manuscritos. El presente diálogo se atribuye en el título al magnífico don Diego Saavedra y no tenemos motivo fundado para poner en entredicho tal atribución, aunque el famoso Nicolás Antonio no lo mencione entre las obras de Saavedra en su Bibliotheca Hispana nova T. I, pág. 241. Sin embargo, no podemos afirmar con certeza sólo por el silencio de Antonio que él no haya sido el autor de este escrito dado que el polígrafo tampoco proporciona noticia de otras de las obras de Saavedra en su Bibliotheca. De guiarnos por ese criterio tampoco podríamos atribuirle la Republica literaria, de la que nos dejó un manuscrito, aunque todas las ediciones con la excepción de la primera se publicaron bajo su nombre. Nosotros mismos tenemos tres ediciones a mano, la primera es la de Alcalá de 1677, impresa en $12^{\circ}$; la otra es la de Madrid de 1735 en $8^{\circ}$ del famoso don Gregorio Mayans y la tercera es la de Londres, que fue reeditada por Pedro Pineda en 1744 en $8^{\circ}$. Además del hecho de que en nuestro manuscrito se le atribuya el diálogo a Saavedra hay otras evidencias en favor de esta hipótesis.

Tras la lectura de este diálogo cualquier lector puede suponer que su autor hubo de ser un hombre de agudo ingenio con mucha experiencia en la historia de los estados europeos y que la obra se escribió en tiempos de la Paz de Westfalia. ¿Y quién se halla entre los hombres de estado españoles de aquellos tiempos con más conocimientos de tales cosas que Saavedra? ¿Quién escribía en aquellos tiempos de forma más ingeniosa sobre esos temas que aquel gran español? No sólo había estudiado en Salamanca, donde se doctoró en Derecho, sino que aumentó su saber sobre las cortes europeas y la política con su paso por Roma, Suiza, Viena, Ratisbona y Münster. Poseía particularmente grandes conocimientos acerca de arte e historia de los estados, como atestiguan su Idea de un Príncipe Político Christiano, representada en cien empresas, que fue traducida a muchos idiomas, y su Corona gótica. En aquélla se revela una persona muy culta, con muchas lecturas y temeroso de Dios, que aborrece algunas afirmaciones impías de Niccolò Machiavelli como por ejemplo en su symbolo XLIII. ${ }^{25}$ En la otra obra da muestras de ser un historiógrafo

25. [«El hombre justifica sus acciones y las mide con la equidad, no queriendo para otro lo que no quisiera para sí. De donde se infiere cuan impío y feroz es el intento de Maquiavelo, que 
muy elocuente, aunque no siempre comprobara la veracidad de las narraciones de un Flavio Dextro, de un Marco Máximo o de Luitprando ${ }^{26}$ ni tampoco se sirviera de las obras de historiadores más antiguos. ${ }^{27}$

Destaca poderosamente su estilo ingenioso, empleado en la República literaria, y al igual que en ella juzga aquí también las artes y los eruditos de los tiempos antiguos y presentes con severidad e ingenio, que también emplea, junto con la misma agudeza, para hablar en el presente diálogo de asuntos europeos. Por lo que se refiere a la fecha de su redacción, encontramos en el mismo texto algunos

forma a su príncipe con otro supuesto o naturaleza de león y de raposa, para que lo que no pudiere alcanzar con la razón, alcance con la fuerza y el engaño». Saavedra Fajardo (1999: 525)].

26. Fue justamente este aspecto lo que censuró el famoso Mayans en su Oración en alabanza de las obras de Don Diego Saavedra Fajardo, pág. XXXIII diciendo: Siento muchisimo ver alli citados, aquellos abominables partos de falsedades indignas, que produjo el capricho del Padre Gerónimo Román de la Higuera, y de Antonio de Nobis, conocido por el nombre de Don Antonio Lupián Zapata, y otros tales; digo a Flavio Dextro, Marco Máximo, Luitprando, y los semejantes a estos que tan mal empleados ilustraron, Don Tomás Tamayo de Vargas, Don Lorenzo Ramírez de Prado, el Licenciado Rodrigo Caro, y algunas [sic] otros, que per il camino que viviendo se hicieron plausibles, en opinión del vulgo; han conseguido ser despreciados de la posteridad atenta al examen de la verdad. Habló de estos y otros falsarios de forma detallada y sincera el culto monje dominico Jacinto Segura en la segunda parte de su Norte Critico, publicado en Valencia por Antonio Balle en 1736 en $4^{\circ}$, págs. 107-207.

27. El famoso padre Vogt cita en la tercera edición de sus Catalogi librorum rariorum [1753], pág. 594 algunos juicios sobre esta Corona Gótica, que no quiero repetir aquí. [Vogt (1747: 594): «Opus doctum, egregium, praestantissimum, judice Chisletio apud Franckenau in $\mathrm{Bi}$ blioth. Hispan. p. 97 (Accesible on line: http:// www.archive.org/details/gerhardiernesti00frangoog). Insigniter dolendum alteram partem ob praematuram Autoris mortem non prodiisse. De máxima autem hujus Libri raritate vid. Bibliotheca Historica Struvio-Buder, pag. 265 \& Catalogus Biblioth. ill. a Ludewig, p. 931 cujus tamen editio ab hac, quam possideo, diversa est».] Me gusta particularmente lo que el can- ciller von Ludewig en Halle apuntó en su ejemplar: Auctor coronae Gothicae clarum nomen habet. Describit hic veteres Gothorum reges ab anno 382 ad a. 716 multo quidem \& longo rerum auctorumque adparatu, verum selectu non adeo magno. Nam laudat in rebus vetustissimis scriptores recentiores, quibus parum inest fidei \& auctoritatis: praeteritis marmoribus, lapidibus, numis, quibus Hispania etiam Gothica non caret \& $c$. [Para Johann Peter von Ludewig (*1670), «königlich preußischer geheimer auch Regierungs- und Consistorialrath des Herzogthums Magdeburg und der Friedrichsuniversität zu Halle Kanzler, der juristischen Fakultät Ordinarius, Direktor des Almosenamts», véase Brucker (1741: I).] A esto quisiera ańadir el juicio sobre esta Corona Gótica del famoso Don Gaspar Ibañez, Marqués de Mondejar, en su Noticia y Juizio de los mas principales Escritores de la Historia de España \& c.: La Corona Gotica de Saavedra, por la cultura y pureza del estilo y por la discreción con que está formada, merece con gran razón se lea más de una vez. Finalmente habrá que recordar que el famoso conde sueco Sparwenfeld [Johan Gabriel Sparwenfeld (1655-1727) era un filólogo, diplomático y coleccionista de documentos históricos sueco.] tradujo esta Corona al sueco y preparó su impresión. Sin embargo se imprimió sólo el primer folio; el ejemplar del conde se halla en la biblioteca universitaria de Uppsala según informa el culto señor Olaus Celsius en Historia Bibliothecae Upsaliensis, pág. 50. [Celsius (1745: 50): «Ut sunt inter alia, Svecana versio operis Saavedra, quod Corona Gothica inscribitur, quam eo usque perduxit illustris auctor, ut primas etiam plagulas typis mandarit, Carolo Regi dicatas [...]». Actualmente hemos iniciado una línea de investigación para localizar esta traducción de Corona Gótica y para estudiar la recepción de Saavedra en Suecia.]. 
indicios cronológicos, como que se mencione en él la toma de Dunkerque por los franceses con la ayuda de los neerlandeses; sabido es que ésta tuvo lugar en 1646 y por consiguiente no podría haberse escrito antes. ${ }^{28}$ Asimismo se cifra en él la edad del estado holandés en 70 años, que cuadra, si se piensa en la unión celebrada en Gante en 1576, como fecha en la cual los holandeses empezaron a liberarse del yugo español y a la que sumándole 70 años llegamos justamente al año 1646.

Es muy probable que Saavedra haya terminado este diálogo en este año o en el siguiente, ya que en 1648 se firmó la paz entre españoles y holandeses en Münster y en ese mismo año murió Saavedra en Madrid. ${ }^{29}$ Saavedra llegó a Münster el 7 de noviembre de 1643 como embajador plenipotenciario español ${ }^{30}$ y en la autorización del rey Felipe IV, otorgada en Madrid el 11 de junio de dicho año, se le alaba con toda justicia por su prudencia, su juicio, su experiencia, así como sus demás virtudes, aunque particularmente por su celo frente al letargo generalizado, ${ }^{31}$ que demostró especialmente en las negociaciones que llevó a cabo en Münster para conseguir la paz. Realizó visitas a los plenipotenciarios franceses, condes d'Avaux y Servien, a cada uno por separado, ${ }^{32}$ en las que in-

28. De hecho, el texto no hace referencia en ningún momento a la culminación de la toma de Dunkerque por parte de los franceses, sino a su vehemente intención de conquistar la ciudad: «Y así es muy de temer que con la diversión de Holanda ocupen franceses a Dunquerque, y que con él se hagan señores del País Bajo» (Saavedra, 2008: 414). Las tropas francesas empezaron el sitio de Dunkerque el 7 de Septiembre de 1646 con la ayuda de los holandeses y la ciudad acabó capitulando el 11 de octubre del mismo año.

29. Véase Aubertum Miraeum De Scriptoribus Saeculi XVII pág. 323. edit. Fabricanae. [Bibliotheca ecclesiastica (1718: 327): «Didacus Saavedra Faxardus, Eques ord. Militaris S. Jacobi, in supremo Indiarum Senatu Consiliarius, \& Plenipotentiarius Regius in Conventu Monasteriensi pro pace generali inter Reges componenda Legatus, vir \& natalibus \& ingenii praestantia nobilissimus, agendarumque rerum peritissimus, edidit Ideam Principis Politici Christiani centum Emblematibus illustratam, quam dedicavit Serenissimo Hispaniarum Principi Balthasari Carolo. Item Coronam Gothicam, Castellanam \& Austriacam, politicis Notis illustratam. Obiit Madriti, anno 1648»].

30. Véase los Actorum pacis Westphalicae del señor Johann Gottfried von Meiern, t. I, pág. 58. [Meiern (1734-1736: 58) : Am $6^{\text {ten }}$ Novembris langete auch Don Diego Saavedra, als Spa- nischer Gesandter zu Münster an. Ihm wurde von dem Kayserlichn Gesandten Graff von Nassau eine Kutsche mit 6 Pferden nebst dazu gehöriger Bedienung entgegen geschickt $[\ldots]$ («El día 6 de noviembre llegó también don Diego Saavedra a Münster. El legado imperial, el conde de Nassau, le envió un coche de seis caballos con los sirvientes correspondientes»].

31. Su autorización se halla en español y en francés en el t. I. pág. 144 de las dichas negociaciones. [Negotiations secrètes touchant la paix de Munster et Osnaburg: «Pouvoir de la part de Philippe IV Roi d'Espagne à Saavedra, pour traiter en son nom de la Paix à Munster, où autre part, avec le Roi de France et ses alliés. A Madrit, le 11 Juin 1643»]

32. T. II. pág. 30. [«Mémoire envoyé à la cour avec la susdite Dépèche: Nous avons été un peu surpris ces jours passés de voir qu'en une visite que chacun de nous a reçue séparement de $\mathrm{Mr}$. Saavedra, il s'étoit voulu entremettre de notre accommodement avec l'Ambassadeur de Venise, et qu'après nous avoir dit que c'étoit un habile homme qu'il falloit considérer, il nous ait voulu faire connoitre qu'il étoit absolument nécessaire dans la Médiation, y ajoutant que l'on ne pouvoit pas nier que Mr. le Nonce ne fut fort honnête homme, mais que l'autre est un grand sujet, et qu'il ne seroit pas possible, que la Negociation put estre faite, sans son entremise»]. 
sistió mucho en la paz entre Espańa y Francia. ${ }^{33}$ En una carta a la reina del 16 de julio de 1644 se recoge que obligó a ambos a alabarle como un negociador muy hábil ${ }^{34}$ precisamente los mismos que le acusaron en una carta al cardenal Mazarin del 22 de octubre de 1644 de algunos engańos (impostures) porque les había ocultado el contenido de una carta interceptada del propio cardenal francés: en ella se daba noticia de que se concluiría el tratado de paz en Viena y en las cortes de España y de Francia, así como también de que la reina de Francia había hablado a don Francisco de Mello acerca de la paz cuando estaba en Senlis. ${ }^{35}$ Le acusan asimismo en una carta al señor de Brienne del 5 de noviembre de 1644 de una audaz maniobra, que consistió en haber inducido a pensar en varias cartas que los franceses habían comenzado ya unas inexistentes negociaciones de paz. Cuentan, asimismo, que los españoles, y entre ellos Saavedra en primer lugar, se empeñaron en entorpecer las negociaciones en Münster. ${ }^{36}$ Así, el men-

33. Ibid. pág. 30. [«Le même Saavedra a déjà voulu entrer en matière avec nous, et a fait réprésenter par l'ambassadeur de Venice, que, pour faciliter la Paix génerale, il falloit préalablement savoir comme les deux Couronnes éstoient ensemble, et la disposition que les deux Rois avoient pour rétablir entr'eux la bonne intelligence»].

34. T. II. pág. 95 [Lettre de Messieurs d'Avaux et Servien à la Reine, du 16 Juillet 1644: «On nous a fait la faveur de croire aussi que V. M. ne nous auroit pas envoyés simplement pour amuser le tapis, et nous n'oserions pas confirmer l'opinion qu'on a eue qu'Elle nous avoit confié le secret de la Negociation, si cela ne servoit de preuve pour justifier les intentions de V. M. Mr. Saavedra et Mr. le Brun, que nous avons trouvés ici pour l'Espagne, sont très habiles hommes; le premier est fort adroit Negociateur, l'autre a acquis grande reputation dans la Charge, qu'il a exercée jusques-ici dans le Parlement de Dôle»]. 35. T. II. pág. 160. [Lettre de Messieurs d'Avaux et Servien à Monsieur le Cardinal Mazarin, du 22 Octobre 1644: «Nous avons encore à vous rendre compte d'une particularité qui regarde V. E. Dom Diego Saavedra parlant toujours des difficultés qui se trouveront à démêler tant de divers intérêts, et à faire une Paix si generale, disoit n'agueres à Mrs. Les Médiateurs, que vous-même, Monseingeur, l'avez ainsi reconnu, et qu'on a intercepté une de vos Lettres, par laquelle, après avoir raisonné sur cette matière, vous concluez que la Paix se fera par l'entremise de quelques personnes à Vienne, et aux Cours de France et d'Espagne. Mais il ne se contenta pas de leur dire, il se leva de sa place, comme pour aller querir la Lettre en son Cabinet, et offrir de la leur faire voir. Néanmoins, après cette offre et une contenance si hardie, il en demeura-là, et passa à un autre Discours de même nature, assurant ces Mrs. que la Reine a fait faire les ouvertures d'une Paix particulière à Don Francisco de Mello, lors qu'il étoit dernièrement à Senlis. V. E. Saura bien si de telles impostures sont fondés sur quelques Lettres ou Discours, auquel les Enemis donnassent un sens contraire; mais nous avons nié hautement, qu'elle aît écrit ce que dessus et avons assuré sur notre vie que celle ne peut être, non plus que la Proposition de Senlis. Il a paru à celui de nous auquel ce raport fut fait qu'il n'en est rien demeuré dans l'esprit de Mrs. les Médiateurs»].

36. T. II. pág. 168. [Lettre des Messieurs d'Avaux et Servien à Monsieur le Comte de Brienne, du 5 Novembre 1644: «L'aversion qu'ils ont, tant les Imperiaux que les Espagnols, contre cette Assemblée et l'envie continuelle qu'ils ont eue jusquesici de la rompre, ou de la rendre inutile, doivent faire tenir pour constant, que tous les autres moyens pour traiter d'Affaires leur seroient plus agréables. Ce sont les discours ordinaires de Saavedra, qui ne peut s'empêcher de dire continuellement, que ce n'est pas ici où la Paix doit être faite, qu'on n'y est que pour l'apparence et pour contester, que c'est dans la Cour d'un des Princes intéressés, où elle se doit conclure. [...] Ce n'est pas seulement par leurs paroles, qu'ils tâchent de détruire cette Négociation; ils y ajoûtent tous les artifices et les efforts qui sont en leur pouvoir»]. 
cionado señor de Brienne le acusa en una posdata del 8 de noviembre de 1645 ante los embajadores plenipotenciarios franceses de tener pocas lecturas acerca de la historia francesa y de conocer poco las leyes francesas contra los herejes. ${ }^{37}$ Se debe tener presente que Saavedra había reprochado al conde de Servien en una conversación mantenida a comienzos del mes de noviembre de 1645 que la incautación de los bienes de los albigenses por parte de los franceses se llevó a cabo sólo gracias a las bulas papales. ${ }^{38}$ Por esa razón Saavedra fue objeto de los dichos ataques del señor de Brienne, quien añadió que los bienes y cuerpos de los albigenses habían sido confiscados desde la legalidad francesa y sin ninguna necesidad de bulas papales, dado que fueron culpables de herejía y de rebelión contra el rey; Saavedra, por su parte, se vengó de los franceses en el presente diálogo. Por otra parte, el reproche de haberles engañado, mencionado más arriba, no estaba fundado, aunque hay que reconocer que Saavedra interceptó en dos ocasiones en 1644 las misivas de la Corte francesa para averiguar cuáles eran sus intenciones, según cuenta el padre Bougeant en su Histoire du Traité de Westphalie, Libro I., pág. 84, donde relata también que los españoles restituyeron el último paquete a los franceses tras haberlo abierto, con lo cual se quejaron amargamente de los mediadores. ${ }^{39}$ Saavedra reprocha en cambio a los franceses mirar tanto por su conveniencia, y conjeturar que apoderándose de Dunkerque podrían llegar fácilmente a ser señores de los Países Bajos y, después, hacer la guerra a las Provincias Unidas para poder así fortificar su propia monarquía. Cuenta el historiógrafo Serres que Clodoveo había quitado la vida y arrebatado la Galia gótica a Amalarico, rey de los godos, por una razón semejante. Ello me

37. T. II p. II. pág. 199. [Lettre de Mesieur de Brienne à Messieurs les Plenipotentiaires, à Paris, le 8 de Novembre 1645, pág. 201: «Cette Lettre étoit écrite lorsque la vître du huit m’a été rendue; la lisant j’ai trouvé que Mr. Servient s'est bien défendu contra Monsieur Saavedra qui a peu lu nos Histoires, et est peu informé des Loix de la France ancienne, lesquelles, sans demander l'assistance des Bulles des Papes, confisquoient les biens et les corps des Albigeois, pour être tombez dans le crime de l'Hérésie et en celui de la Rebellion au Roi»].

38. Esta curiosa conversación se lee en el t. II, p. II, pág. 197 sigs. [Lettre de Messieurs les Plenipotentiaires à Monsieur de Brienne, a Münster le 8 Novembre 1645. El resumen de la conversación entre Saavedra y Servien se extiende a lo largo de las páginas 197, 198 y 199. Citamos el párrafo concreto que se cita en el prólogo: «Après il reprit en riant le discours de la Navarre pour me dire que s'il falloit examiner les droits de la Couronne de France sur tout ce qu'elle possede, ils se trouveroient tous semblables à ceux de l'Espagne sur la Navarre, puisque les conquêtes qui avoient été faites sur les Albigeois n'etoient fondées que sur les Bulles des Papes»].

39. [L'envie que les Espagnols avoient de découvrir le secret de la France étoit telle, que contre toutes les regles de la bonne soi, ils firent arreter entre Anvers et la Meuse, un courrier chargé des lettres de la Cour de France pour ses Plénipotentiaires. Ils ouvrirent le pacquet et lurent toutes les dépêches; mais ils n'y trouverent pas ce qu'ils cherchoient. [...] Les Espagnols tenterent encore une fois la même chose sans succès, et ils eurent le chagrin d'avoir fait une violence odieuse, sans en retirer aucun fruit. Ils renvoyerent aux Plénipotentiaires François les lettres toutes ouvertes, et ceux-ci ne manquerent pas d'en faire aux Médiateurs des plainte très-aigres, menaçant de traiter de la même manière les courriers d'Espagne qui passoient par la France»]. 
obliga a hacer una pausa y reflexionar: ya se sabe que Saavedra fecha su dedicatoria de Corona Gótica al Príncipe de España en Münster a 8 de septiembre de 1645 y sabemos también que el libro se publicó allí mismo en 1646. Todo lo que resumo aquí en pocas palabras del historiador francés Serres lo desarrolló detalladamente por esas mismas fechas en su Corona Gótica, pág. 132 sigs. En ella analizan las razones por las cuales Clodoveo declaró la guerra a Amalarico. Cita las palabras siguientes de la Antiquité de Gaule \& de France del presidente Fauchet: ${ }^{40}$

Et quand ceste occasion cesseroit, encores estoit ce une entreprise necessaire pour la conservation de l'estat de François: puis qu'ils ne pouvoient asseurer leurs conquestes en Gaule, tant que les Wisigoths entiendroient une si grande portion, $\&$ de l'Espagne.

Y allí mismo cita del Inventaire de l'Histoire de France del ya mencionado Jean de Serres lo siguiente:

Clovis en vouloit aux Wisigoths, qui tenoient un grand et large pays de Gaule, faisant ombre à la Monarchie Françoise, laquelle il desiroit etablir: mais il falloit avoir un honneste pretexte de leur faire la guerre: bienque par effet le droict de bienseance fut son principal droict.

Saavedra mismo describió las razones de la guerra de Clodoveo contra Amalarico así:

Buenas máximas justificar la guerra con la conveniencia, y razón de estado, haziendo defensa natural, despojar al vicino, para asegurarse d'él, con que no habría firme paz entre los confinantes. Quiera Dios que estas mismas máximas injustas y tiranas no se pratiquen en nuestros tiempos.

De esta manera, la llamada ley de la utilidad o de la bienséance, como dice Serres, o conveniencia según Saavedra, puede considerarse según el testimonio de un historiador francés, Serres, como principio de la monarquía francesa y atribuirse su primer empleo al rey Clodoveo. Además, encontramos en la mencionada conversación de Saavedra con el señor Servien en la que quiere conseguir la paz en nombre de su rey algunas ideas que se repiten en el presente diálogo. Esta coincidencia es suficiente - junto con lo que hemos constatado acerca de la Corona Gótica - para asegurar que él fue realmente el autor de este diálogo. En este mismo diálogo dice también que el desprecio de la paz es imprudente. Esto

40. [Fauchet, 1611: livre II, chapitre XXII, 130] 
se puede colegir en una carta del rey de Italia, Teodorico, al rey de Francia, Clodoveo, que Saavedra reprodujo, tomándola de Casiodoro (Variis lib. III. Epist. 4) ${ }^{41}$ en su integridad en Corona Gótica, pág. 138. Cuando Saavedra dice en el presente diálogo, que Tubal vino al principio a España, está repitiendo lo que dijo en Corona Gótica, pág. 146: Poblada España por Tubal \& se estendió por ella su descendencia. Cita allí a Johannis Vasaei y su Chronico Hispaniae c. 10: Thubal venit in Hispaniam, primusque eam habitavit. ${ }^{42}$ Otros eruditos no comparten esta visión de los hechos. Todos estos lugares que hemos citado de Corona Gótica demuestran, en nuestra opinión, que ésta y el presente diálogo deben de ser obra de la misma persona.

Saavedra se mostraba muy afligido cuando en sus negociaciones intentaba sin éxito, a pesar de toda su habilidad, proporcionar a su rey la tan necesaria paz con Francia. No es de maravillar que haya demostrado tan claramente su antipatía hacia unos franceses que han dificultado esta tarea y le han intentado engañar de muchas formas. Ese enojo hacia los franceses también se ha manifestado en una conversación con los embajadores plenipotenciarios del Círculo de Franconia - Cornelius Gobelius, Johann Müller y Tobias Delhafen ${ }^{43}$ — cuando le hicieron una visita en Münster en marzo de 1645. Acusaba a los franceses de haber buscado diferentes subterfugios infundados acerca de sus plenos poderes; decía que los alemanes deberían abrir los ojos y percibir las intenciones de las coronas extranjeras, que buscaban solamente la ruina de Alemania. Deberían asegurar la majestad y la libertad del Emperador y de las Cortes por las armas. Opina también que Francia está agotada a causa de las exigencias sin medida que sufren sus súbditos y lamenta que los alemanes, que en general son personas francas y que él siempre había estimado por su sinceridad y sus otras virtudes destacadas, hubiesen puesto tanta fe en las promesas de los extranjeros en contra de su propia razón de estado, cosa que nunca había leído en las historias griegas, latinas ni persas. Dice que se le saltan las lágrimas en cuanto recuerda estos

41. ["Quae cum ita sint, miramur animos vestros sic causis mediocribus excitatos, ut cum filio nostro rege Alarico durissimum velitis subire conflictum, ut multi, qui vos metuunt, de vestra concertatione laetentur. Ambo estis summarum gentium reges, ambo aetate florentes. Non leviter regna vestra quassatis, si data partibus libertate confligitis. Virtus vestra patriae non fiat inopinata calamitas, quia grandis invidia est regum in causis levibus gravis ruina populorum. Dicam libere, dicam affectuose quod sentio: impatiens sensus est ad primam legationem arma prontius commovere» (Cassiodorus, 2005: 108)].

42. [La cita completa que Saavedra hace en Corona Gótica es la siguiente: «Thubal filius
Japhet, Nepos Noë venit in Hispaniam, primusque eam habitavit post diluvium» (Saavedra, 1946: 814), sacada directamente del Chronicon rerum memorabilium Hispaniae de Juan Vaseo]. 43. El señor Cornelio Gobelio era consejero del obispo de Bamberg y firmó en su nombre la Pax Westfálica. Tobias Delhafen von Schöllenbach (*23 de agosto de 1601 en Nürnberg) fue miembro del consejo de la ciudad de Nürnberg y participó en el congreso de Münster en 1644 como representante de su ciudad. Johann Müller era el delegado de la ciudad de Bayreuth. Los tres representantes de Franconia aparecen citados en la obra de Meiern, t. I, págs. 371, 541 y 551 . 
tristes asuntos. ${ }^{44}$ También le expresó su desasosiego a un diplomático sueco en Münster, el señor von Rosenhahn, ${ }^{45}$ cuando intentaba separar a los suecos de los franceses diciendo que se maravillaba de que su corona no atendiera a sus propios intereses y fueran engañados por las prácticas secretas de Francia. Fingió que Francia había quebrantado siempre los tratados más solemnes alegando ejemplos antiguos que aplicaba a la situación actual. Un jesuita francés, el padre Bougeant, descartó minuciosamente estas acusaciones de Saavedra, aunque le daba siempre el título de conde, lo que no había sido nunca. ${ }^{46}$ Describe a Saavedra como un hombre orgulloso de su nación y de su príncipe; y en cuanto a su forma de tratar los asuntos del estado le atribuye en ocasiones un carácter orgulloso y arrogante, aunque en otras le considera por sus intrigas un enemigo peligroso $^{47}$ sin negar nunca su habilidad.

No sabemos decir con exactitud cuándo partió Saavedra de Münster y regresó a España. Encuentro noticia en las Negociationes secretes de paix de Munster \& d'Osnabrug, t. I., pág. 379 de que Saavedra llegó a Paris el 14 de abril de 1645 y que quería viajar vía Bruselas a España, para luego ir como mandatario a Roma. ${ }^{48}$

44. Véase la Acta Pacis Westphalicae del señor von Meiern, t. I., págs. 375 y 376. [«Dolendum sane Germanos, prudentes alias Viros, \& ob candorem, sinceritatem aliasque egregias animorum dotes ipsi semper charissimos, hactenus exterrorum praetextibus \& promissis, contra proprias status rationes, tantum fidei in plerisque attribuisse, quale ipse neque in historia Romana, neque Graeca, neque in Persica ullum unquam legerit vel audiverit exemplum. Rem plane stupendam adeoque fatali dispositioni merito adscribendam! Nec se temperare a lacrymis, quoties hujus rei $\&$ eventus illius tristissimi cogitatio mentem subeat»].

45. Freiherr Schering Rosenhane (1609-1663), gobernador de Östergötland, fue nombrado cónsul sueco en Münster en junio de 1643.

46. En su Histoire du Traité de Westphalie, t. I. pág. 390. [Tomo II, libro I, pág. 390: «Il lui représenta que puisque la France traitoit avec le Duc de Bavière et les Electeurs Catholique sans les Suédois, il s'étonnoit que ceux-ci ne songeassent point aussi de leur côte à leurs intérêts particuliers. Il soutenoit que les François ne vouloient point la paix, et qu'en moins de six mois la Suède se verroit trompée par leurs practiques secrètes. Il prétendoit que la France avoit de tout tems violé les Traités les plus solemnels. Il en cherchoit des exemples dans l'antiquité et en faisoit des applications aux tems présens.
Il montroit un écrit qu'il avoit fabriqué et qui contenoit les prétendues conditions que la France proposoit au Duc de Bavière. Il ajoutoit que comme la France vouloit traiter séparément de la Suède, elle tâchoit aussi d'engager les Electeurs à traiter avec elle séparément de l'Empereur»].

47. Op. cit., pág. 389. [«Le Comte de Saavedra, ennemi dangereux par ses intrigues, étoit venu à bout de lier un commerce d'amitié avec M. Rosenhan, Résident de Suède à Munster». El mismo Bougeant dedica otras palabras a Saavedra, pág. 17-18, que concuerdan con lo que podemos leer en el prólogo: «Le Compte de Saavedra extrêmement prévenu en faveur de sa nation et de son Prince, avoit dans sa manière de négocier beaucoup de hauteur et de fierté. Il avoit d'ailleurs de l'adresse et il sçavoit dissimuler; mais il parut qu'il n'avoit été envoyé à Munster que pour y attendre l'arrivée d'un Ministre plus expérimenté»].

48. [Pág. 378: Extrait des Nouvelles de Paris: «On écrit levingt uniéme d'Avril de Cologneque le quatorzième dudit mois Dom Diego de Saavedra, ci-devant Plénipotentiaire du Roi d'Espagne pour la Paix générale, arriva de Munster en Cette Ville, d'où il partit le lendemain en poste pour aller à Bruxelles, et delà en Espagne trouver Sa Majesté Catholique, qui le veut envoyer à Rome Ambassadeur Ordinaire»]. 
Sin embargo es probable que el viaje no se hiciera sino más tarde, porque parece ser que a principios de noviembre de 1645 tuvo lugar en Münster su mencionada conversación con el señor Servien. Es probable que su vuelta a España se deba fechar en 1646 como lo hace el padre Bougeant. ${ }^{49}$

Por otra parte, este diálogo está bastante bien construido siguiendo las reglas del arte retórico y los caracteres de los dos interlocutores están bien diseñados. Los juicios de Saavedra son muy severos pero ingeniosos. No los compartimos para nada y hay que decir que llegan a ser poco creíbles en algunas partes. En muchas ocasiones los acontecimientos no siguieron el rumbo que este gran hombre de estado había pronosticado, lo cual puede servir de enseńanza para muchos. Dice también muchas verdades amargas que nos pueden servir de ejemplo y aviso en nuestros tiempos confusos si las queremos entender. Saavedra expresó en otro lugar, en la Idea de un principe, simb. LXXXI, elogiada más arriba, sus ideas acerca de Alemania y de la nación alemana con mucha sinceridad, diciendo que allí habían florecido todas las artes y que tenía soldados muy valientes. ${ }^{50}$ Desearíamos que esta doble gloria de nuestra querida patria se conservara en los tiempos venideros y que se curara de los defectos mencionados. Esperamos sobre todo que en el presente año del Señor 1748 sea otra vez una ciudad alemana — como lo fueron hace cien años Münster y Osnabrück— en la que se restablezca la deseada paz después de tanto derramamiento de sangre y que se prevalezca el equilibrio en Europa y la libertad en Alemania.

Para terminar pedimos al estimado lector de este diálogo que haga amablemente caso omiso de las faltas que puede haber en la presente traducción alemana.

49. En la lista de los Plenipotentiaires, en apéndice del segundo tomo de su Histoire. [En realidad la mencionada lista se encuentra al final del tercer tomo de la Histoire de Bougeant (1644), concretamente en las páginas 643-652.]

50. [ "En Alemania la variedad de las religiones, las guerras civiles, las naciones que militan en ella han corrompido la candidez de sus ánimos y su ingenuidad antigua. Y como las materias más delicadas, si se corrompen, quedan más dañadas, así donde ha tocado la malicia extranjera ha dejado más sospechosos los ánimos y más pervertido el buen trato. Falta en algunos la fe pública. La injurias y los beneficios escriben en cera, y lo que se les promete en bronce. El horror de tantos males ha encrudecido los ánimos y ni aman ni se compadecen. No sin lágrimas se puede hacer paralelo entre lo que fue esta ilustre y heroica nación y lo que es, destruida no menos con los vicios que con las armas de la obras. $\mathrm{Si}$ bien en muchos no ha podido más el ejemplo que la Naturaleza, y conservan la candidez y generoso trato de sus antepasados, cuyos estilos antiguos muestran en nuestro tiempo su bondad y nobleza. Pero, aunque está así Alemania, no le podemos negar que generalmente son más poderosas en ella las buenas costumbres que en otras partes las buenas leyes. Todas las artes se ejercitan con gran primor. La nobleza se conserva con mucha atención; de que puede gloriarse entre todas las naciones. La obediencia en la guerra y la tolerancia es grande, y los corazones animosos y fuertes. Hase perdido el respeto al Imperio, habiendo éste, pródigo de sí mismo, repartido su grandeza entre los príncipes y disimulado la usurpación de muchas provincias y la demasiada libertad de las ciudades libres, causa de sus mismas inquietudes, por la desunión deste cuerpo poderoso». (Saavedra Fajardo, 1999: 883-884)]. 


\section{Bibliografía}

Bas Carbonell, Manuel, «Viajeros alemanes por Valencia», Viajar para saber: movilidad y comunicación en las Universidades europeas, Salvador Albiñana (ed.), [Exposició Sala Estudi General, La Nau, Universitat de València 5 octubre - 21 noviembre 2004], Valencia, Universitat de València, 2004, 201-221.

BlecuA, Alberto, "Las repúblicas literarias y Saavedra Fajardo», Edad de Oro, 3 (1984) 67-97.

—, Signos viejos y signos nuevos, Barcelona, Crítica, 2006.

Boadas Cabarrocas, Sònia, «La transmisión textual de Locuras de Europa», Boletín de la Real Academia Española, en prensa.

Bougeant, Guillaume Hyacinthe, Histoire du traité de Westphalie, ou des négociations qui se firent à Munster et à Osnabrug pour établir la Paix entre toutes les puissances de l'Europe, París, Didot, 1744. Accesible online: http://www. archive.org/details/histoiredutrait00bouggoog.

Brauer, Adalbert, «Nachkommen des Leipziger Verlagsbuchhändlers Johann Friedrich Gleditsch: Vorfahren, Verwandtschaftskreis und soziologische Struktur", Börsenblatt für den deutschen Buchhandel, 20 (1960) 917-926.

Brucker, Jakob, Bilder-Sal heutiges Tages lebender und durch Gelahrtheit berühmter Schriftsteller, Augsburgo, Johann Jakob Haid, 1741.

BRUnet, Jacques-Charles, Gustave Brunet, Manuel du libraire et de l'amateur de livres, París, Firmin-Didot, 1864. Accesible online: http://www.archive.org/search.php?query=Manuel $\% 20 \mathrm{du} \% 20$ libraire $\% 20$ et $\% 20 \mathrm{de} \% 20$ l'amateur\%20de\%20livres.

Cassiodorus, Flavius Magnus Aurelius, Variae, Lorenzo Viscido (ed.), Cosenza, Pellegrini Editore, 2005.

Celsius, Olof, Bibliotheca Upsaliensis historia, Uppsala, s.i., 1745. Accesible online: http://www.archive.org/details/bibliothecaeupsa00upps.

—, Uppsala universitetsbiblioteks historia, Sten Hedber (trad.) \& Gert Hornwall (ed.), Uppsala, Almqvist \& Wiksell, 1971.

Claude Fauchet, Les antiquitez Gauloises et Françoises: augmentées de trois livres; contenans les choses advenuës en Gaule et en France jusques en l'an 751, Perier, París, 1599 [Reimpresión Ginebra, Paul Marceau, 1611].

"Die gelehrte Republic, durch Don Diego Saavedra» (Reseña de Lobrede auf die Werke Saavedras de J. E. Kapp, Leipzig: Gleditsch), en Neuer Büchersaal der schönen Wissenschaften, 7.1 (julio de 1748), 54-72. Accesible online en http://gdz.sub.uni-goettingen.de/dms/load/img/?PPN=PPN556860969_0 007\&DMDID=DMDLOG_0006. (Consultado el 1.9.2010).

Dowlung, John Clarkson, Diego de Saavedra Fajardo, Boston, Twayne Publishers, 1977.

García López, Jorge, «Los testimonios manuscritos de la segunda redacción de República Literaria», Boletín de la Real Academia Española, 82 (2002) 79-111. 
—, «Introducción biográfica y crítica», Saavedra Fajardo, Diego de, República Literaria, Jorge García López (ed.), Barcelona, Crítica, 2006.

Gierl, Martin, Pietismus und Aufklärung, Gotinga, Vandenhoeck \& Ruprecht, 1997.

Grässe, John George Theodore, Tresor de livres rares et precieux ou Nouvean Dictionnaire Bibliographique, Dresde, Rudolf Kuntze, 1865.

Mayans y Siscar, Gregorio, Epistolario. Mayans y los libreros, Antonio Mestre (ed.), Valencia, Publicaciones Ayuntamiento de Oliva, 1993.

-, Epistolario: Mayans y el Barón de Schönberg, Santiago Aleixos \& Antonio Mestre (eds.), Valencia, Universitat de València, Departamento de Historia Moderna, 2002.

Meerman, Gerard, Bibliotheca Meermanniana: sive Catalogus librorum impressorum et codicum manuscriptorum; quos maximam partem collegerunt Gerardus et Joannes Meerman, La Haya, Comitum, 1824.

MeIERn, Johann Gottfried von, Acta pacis westphalicae publica, Hanóver, Gercken, 6 vols., 1734-1736.

Mencke, Friedrich Otto \& Johann Burkhard Mencke, Bibliotheca Menckeniana, quae autores praecipue veteres graecos et lat. historiae item literariae, eccl. et civilis, antiquitatum ac rei nummeriae scriptores, philologos, oratores, poetas et codices mss. complectitur, Lipsia, Gleditsch, 1727. Accesible online una edición de 1723: http://www.archive.org/search.php?query=Bibliotheca $\% 20$ Menckeniana.

Mestre, Antonio, «Mayáns, die spanische Kultur und Deutschland im 18. Jahrhundert", Eine Ausstellung aus den Beständen der Niedersächsischen Staatsund Universitätsbibliothek Göttingen, Elmar Mittler \& Ulrich Mücke (eds.), Gotinga, s.i., 2005, 55- 66.

Miraeus, Aubertus, Bibliotheca ecclesiastica, Hamburgo, Liebezeit \& Felginer, 1718.

Négociations secrètes touchant la Paix de Münster et d'Osnabrück, La Haya, Jean Neaulme, 1725.

Palau i Dulcet, Antonio, Manual del librero hispanoamericano, Barcelona, Palau i Dulcet, 1980.

Roche, Conde de y José Pío Tejera, Saavedra Fajardo. Sus pensamientos, sus poesías, sus opúsculos, Madrid, Imprenta de Fortanet, 1884.

SaAvedra Fajardo, Diego de y Antonio Brun, Antwort der Königlichen Hispanischen Herren Abgesandten auff die von der Cron Franckreich bey angestellten Friedens Tractaten zu Münster inn Westphalen gethane Proposition, [S.l.]: [S. i.] 1645. Accesible online: http://vd17.bibliothek.uni-halle.de/ pict/2005/3:673551Y/. (Consultado el 1.9.2010)

SAavedra Fajardo, Diego de, Locuras de Europa, s.l., s.i., 1748a.

—, Die Thorheiten von Europa, s.l., s.i., 1748b.

—, Die Gelehrte Republik, Lipsia, In der Gleditschischen Buchhandlung, 1748c.

—, Locuras de Europa, en Semanario Erudito, 5.6. (1787), 3-44. Accesible on- 
line: http://www.archive.org/stream/semanarioerudit02sotogoog\#page/n7/ mode/1up (p. 365 del volumen que contiene las dos revistas)

-, Republica literaria y diálogo de las Locuras de Europa, Madrid, Imprenta de García, 1819. Accesible online: http://www.archive.org/details/republicalitera00siscgoog

—, Obras completas, Ángel González Palencia (ed.), Madrid, Aguilar, 1946.

—, Empresas Políticas, Sagrario López Poza (ed.), Madrid, Cátedra, 1999.

-, Locuras de Europa, Sònia Boadas Cabarrocas (ed.), en Rariora et Minora, Murcia, Tres Fronteras, 2008b, 303-316.

Salvá Pérez, Vicente, Pedro Salvá y Mallen, Catálogo de la Biblioteca de Sal$v a ́$, Valencia, Imprenta de Ferrer de Orga, 1872. Accesible online: http:// ia311227.us.archive.org/3/items/catlogodelabib01 salvuoft/catlogodelabib01salvuoft.pdf http://ia351433.us.archive.org/2/items/catlogodelabibl00mallgoog/catlogodelabibl00mallgoog.pdf http://ia311204.us.archive. org/1/items/catlogodelabib02salvuoft/catlogodelabib02salvuoft.pdf http:// ia351426.us.archive.org/1/items/catlogodelabibl01 mallgoog/catlogodelabibl01 mallgoog.pdf

Serres, Jean de, Inventaire Général de l'histoire de France, París, A. Saugrain \& G. des Rues, 1597.

VogT, Johann, Catalogus historico-criticus librorum rariorum, iam curis recognitus Bibliophilorum doctissimorum adauctus, Hamburgo, Herold, 1747. Accesible online: http://www.archive.org/search.php?query=Catalogus\%20historicocriticus\%20librorum\%20rariorum http://www.archive.org/details/iohannisvogtcat00vogtgoog 